\title{
Interaction of ciprofloxacin chlorination products with bacteria in drinking water distribution systems
}

\author{
Haibo Wang ${ }^{\mathrm{a}}$, Chun $\mathrm{Hu}^{\mathrm{a}, \mathrm{b}, *}$, Lizhong Liu ${ }^{\mathrm{a}, \mathrm{b}}$, Xueci Xing ${ }^{\mathrm{a}, \mathrm{b}}$ \\ a Key Laboratory of Drinking Water Science and Technology, Research Center for Eco-Environmental Sciences, Chinese Academy of Sciences, Beijing, \\ 100085, China \\ b University of Chinese Academy of Sciences, Beijing, 100049, China
}

\section{H I G H L I G H T S}

- Interaction of ciprofloxacin chlorination products with bacteria was investigated.

- Chlorination can't mineralize ciprofloxacin, but can destroy the piperazine ring.

- Chlorination initiated biotranformation of ciprofloxacin chlorination products.

- Genotoxicity decreased clearly due to synergistic effect of chlorine and bacteria.

- Biotransformation of chlorination products increased antibiotic resistance genes.

\section{A R T I C L E I N F O}

\section{Article history:}

Received 26 April 2017

Received in revised form 14 June 2017

Accepted 15 June 2017

Available online 17 June 2017

\section{Keywords:}

Ciprofloxacin chlorination products

Biotransformation

Bacterial community

Antibiotic resistance genes

Genotoxicity

\section{G R A P H I C A L A B S T R A C T}

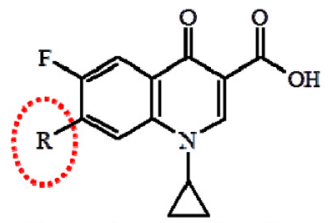

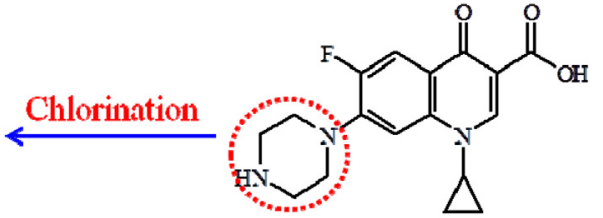

Ciprofloxacin chlorination products

Ciprofloxacin

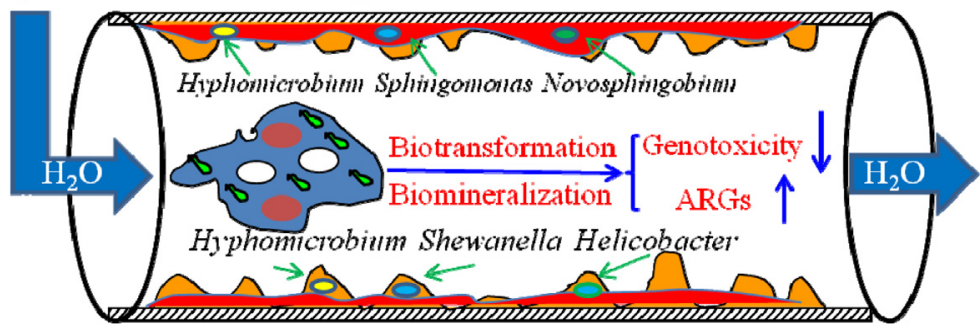

\begin{abstract}
A B S T R A C T
The interaction of ciprofloxacin chlorination products (CIP-CPs) with bacteria in drinking water distribution systems (DWDSs) was investigated. The piperazine ring of CIP was destroyed by chlorination. Among of CIP-CPs, by the bacterial role, $7.63 \%$ of the derivative with two carboxylic groups went through decarboxylation to form desethylene ciprofloxacin, and then loss of $\mathrm{C}_{2} \mathrm{H}_{5} \mathrm{~N}$ group generated aniline compound. Furthermore, $12.3 \%$ of the aniline compound, $7.60 \%$ of chlorinated aniline compound and $1.35 \%$ of defluorinated product were bio-mineralized. Therefore, the chlorine and bacteria played synergistic effects on transformation of CIP-CPs in DWDSs, contributing to the obvious decrease of genotoxicity in effluents. Correspondingly, the $\mathrm{TEQ}_{4-\mathrm{NQO}}$ decreased from $667 \mu \mathrm{g} / \mathrm{L}$ to $9.41 \mu \mathrm{g} / \mathrm{L}$. However, compared with DWDSs without CIP-CPs, the relative abundance of mexA and qnrS increased 1-fold in effluents and the relative abundance of qnrA and $q n r B$ increased 3-fold in biofilms in DWDSs with CIP-CPs. mexA and qnrS positively correlated with Hyphomicrobium, Sphingomonas and Novosphingobium $(\mathrm{p}<0.05)$, while qnrA and qnrB positively correlated with Shewanella and Helicobacter $(\mathrm{p}<0.05)$, indicating
\end{abstract}

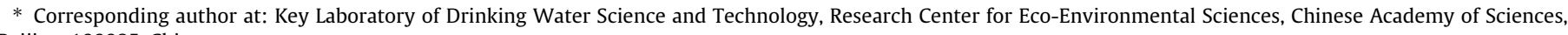
Beijing, 100085, China.

E-mail address: huchun@rcees.ac.cn (C. Hu). 
the increase of antibiotic resistance genes (ARGs) came from the growth of these bacterial genera by transformation of CIP-CPs in DWDSs. These results suggested that biotransformation of antibiotics might increase ARGs risk in DWDSs.

(c) 2017 Published by Elsevier B.V.

\section{Introduction}

Fluoroquinolones are a family of synthetic, broad-spectrum antibiotics, used to treat diseases in both humans and animals [1]. They are frequently detected in groundwater and surface water because of insufficient removal of these compounds by conventional wastewater treatment operations [2-4]. Fluoroquinolones contribute to the emergence and spread of antibiotic resistant bacteria (ARB) and antibiotic resistance genes (ARGs) [5,6]. Moreover, these antibiotics increase the toxicity of source water [3], and this will pose risks to human health.

A representative antibiotic of fluoroquinolone class is ciprofloxacin (CIP), which has been extensively used over the past 20 years [7]. The concentration of CIP in source water is generally low, typically in $\mu \mathrm{g} / \mathrm{L}$ or $\mathrm{ng} / \mathrm{L}$ level $[3,8]$. Ineffective removal of CIP by conventional water treatment technologies has caused the detection of CIP in drinking water in $\mathrm{ng} / \mathrm{L}$ level $[9,10]$. However, the low concentration of CIP is toxic to some aquatic organisms [11], and it works against gram-negative and gram-positive bacteria through inhibition of bacterial DNA unwinding and duplicating [12]. CIP can also affect the bacterial community composition in aquatic environment $[7,13]$, and its impact on microbial communities is selective [14]. Moreover, bacterial community shift drives antibiotic resistance promotion during drinking water chlorination [5]. Therefore, in order to control the water contamination by CIP, many studies have investigated the degradation of CIP by different water treatment technologies, including chlorination, ozonation and other advanced oxidation process $[1,4,15,16]$. CIP is degraded quickly during these treatments, however, its mineralization is very difficult and some intermediates containing quinolone ring were produced usually. The toxicity of CIP is slowly diminished due to its degradation, but in some cases the degradation products of ciprofloxacin appear to have a higher toxicity than the parent compounds [17].

The drinking water usually goes through the drinking water distribution systems (DWDSs) before reaching the user points. DWDSs are an important component in the provision of safe drinking water to consumers, although often overlooked [18]. Maintaining chlorine residual is widely used for controlling microbial contamination in DWDSs. During water chlorination, the piperazine ring of CIP can quickly react with chlorine to form other degradation products including quinolone ring $[1,19]$. Therefore, the micropollutants were CIP chlorination products (CIP-CPs) rather than CIP in finished drinking water $[5,8]$. CIP-CPs with quinolone ring will affect the bacterial community in DWDSs, because the antibacterial activity of CIP is mainly caused by the quinolone moiety [20]. Moreover, biotransformation of CIP by bacteria and fungus in water have been found in some other studies, although this process is very slowly $[21,22]$. Therefore, CIP-CPs may also go through biotransformation by the bacteria in DWDSs, which can affect the water quality in DWDSs. It has been reported that the genotoxicity of tap water was higher than that of finished drinking water in some conditions [23], however, there is little known about the interaction of CIPCPs and the bacterial community composition, and its effect on the genotoxicity of water in DWDSs.

The aims of this study were (1) to investigate the CIP chlorination process and the biotransformation of CIP-CPs, and their effects on genotoxicity changes in DWDSs; (2) to analyze the bacterial community and ARGs shift, and reveal the interaction between the CIP-CPs and bacteria in DWDSs.

\section{Materials and methods}

\subsection{Materials}

Sodium hypochlorite $(\mathrm{NaClO})$ solution, analytical grade, was purchased from Sinopharm Chemical Reagent Co., Ltd (China). Ciprofloxacin (CIP), high performance liquid chromatography (HPLC) grade, was obtained from Sigma-Aldrich Fluka (USA).

The tested raw water was collected from a drinking water treatment plant in north of China, which was treated by coagulation, flocculation, sedimentation, sand filtration, and biologicallyactivated carbon filtration (prior to entering the chlorine contact tanks). All water samples were stored at $4{ }^{\circ} \mathrm{C}$ before using. Water quality parameters were measured according to standard methods [24] (Table S1). Dissolved organic carbon (DOC) was analyzed via a total organic carbon analyzer (TOC-V $\mathrm{V}_{\mathrm{CPH}}$, SHIMADZU, Japan). Differences of water quality were measured using analysis of variance (ANOVA) with a significance threshold of $\alpha=0.05$.

\subsection{Experiments design}

Firstly, in order to know the reaction of CIP with chlorine, three 1.5 L glass fiber-reinforced plastic bottles were used in this study. One was filled with $1 \mathrm{~L}$ raw water with addition of $1 \mathrm{mg} / \mathrm{L}$ chlorine, the other one was filled with $1 \mathrm{~L}$ raw water with addition of $1.6 \mathrm{mg} / \mathrm{L}$ CIP and $1 \mathrm{mg} / \mathrm{L}$ chlorine, the third one was filled with $1 \mathrm{~L}$ ultrapure water with addition of $1.6 \mathrm{mg} / \mathrm{L} \mathrm{CIP} \mathrm{(DOC} 1 \mathrm{mg} / \mathrm{L}$ ) and $1 \mathrm{mg} / \mathrm{L}$ chlorine. Each experiment was done in triplicate. After 2 and $50 \mathrm{~h}$, the DOC, chlorine residual and CIP concentration of different waters were analyzed, and the CIP-CPs were also analyzed.

Secondly, the transformation of CIP-CPs in DWDSs was studied. Ten cast iron coupons were immersed in covered $1.5 \mathrm{~L}$ glass fiberreinforced plastic bottles to simulate the DWDSs. The information of cast iron coupons was described in the Supplementary Material (Text S1). Before this study, six simulated DWDSs have been run at the same conditions for more than two years, and the stable corrosion scales have been formed on the surface of the cast iron coupons. In one experiment, after $1 \mathrm{~L}$ raw water was chlorinated for $2 \mathrm{~h}$ with $1 \mathrm{mg} / \mathrm{L}$ chlorine, it was added into one DWDS. In the other experiment, after $1 \mathrm{~L}$ raw water with addition of $1.6 \mathrm{mg} / \mathrm{L}$ CIP was chlorinated for $2 \mathrm{~h}$ with $1 \mathrm{mg} / \mathrm{L}$ chlorine, it was also added into one DWDS. The water in each DWDS was displaced with fresh water at $48 \mathrm{~h}$ intervals and gently agitated by a magnetic rotor to mix the water, reflecting dead zones or worst case conditions in actual water distribution systems according to the reported methods $[25,26]$. The bulk water was also sampled at $48 \mathrm{~h}$ intervals to measure the DOC and CIP-CPs concentrations. The two experiments were run in triplicate for 250 days, respectively, and the experiment without CIP was performed as a control. Moreover, in order to know the biotransformation of CIP-CPs in DWDSs, from 40 to 60 days, after $1 \mathrm{~L}$ ultrapure water with addition of $1.6 \mathrm{mg} / \mathrm{L} \mathrm{CIP}$ was chlorinated for $2 \mathrm{~h}$ with $1 \mathrm{mg} / \mathrm{L}$ chlorine, it was also added into one DWDS after the water, and DOC was analyzed. 


\subsection{Ciprofloxacin analytical methods}

The concentration of CIP was measured using high-performance liquid chromatography (HPLC, 1200 series; Agilent) with a Zorbax SB-Aq column $(5 \mu \mathrm{m}, 4.6 \times 250 \mathrm{~mm}$; Agilent). The analysis was carried out at $278 \mathrm{~nm}$ using a $20 / 80 \% \mathrm{v} / \mathrm{v}$ mixture of acetonitrile/phosphoric acid ( $\mathrm{pH} 2.5$ ) as mobile phase.

For identification of CIP-CPs, samples were filtered and the filtrates were concentrated by solid phase extraction (SPE) method consisting of an HLB cartridges ( $200 \mathrm{mg} / 6 \mathrm{~mL}$ ) (Waters Oasis). The cartridges were initially conditioned with $10 \mathrm{~mL}$ of methanol. $50 \mathrm{~mL}$ sample was loaded onto the cartridges at a $15 \mathrm{~mL} \mathrm{~min}^{-1}$ flow rate. The compounds were then eluted off from the cartridges with $5 \mathrm{~mL}$ methanol and $5 \mathrm{~mL}$ Milli Q water. The eluent was evaporated to dryness under a gentle stream of nitrogen and then reconstituted with $1 \mathrm{~mL}$ of water-methanol mixture $(1: 1 \mathrm{v} / \mathrm{v})$, resulting in 50 fold concentration of analytes. The samples after concentration were analyzed by ultra high-performance liquid chromatography \& quadrupole time-of-flight mass spectrometer (UPLC-Q-TOF-MS, ACQUITY UPLC/Xevo G2 Q-TOF, Waters), using electrospray ionization (ESI) in positive mode, over a mass-to-charge range of $\mathrm{m} / \mathrm{z}$ 50-600. An ACQUITY UPLC ${ }^{\circledR}$ HSS T3 column $(1.8 \mu \mathrm{m}, 2.1 \times 50 \mathrm{~mm})$ was used with a mobile phase containing water $(0.1 \%$ formic acid) as eluent $A$ and acetonitrile ( $0.1 \%$ formic acid) as eluent $B$. The linear gradient was from 5\% B to $70 \%$ B in $20 \mathrm{~min}, 70 \%$ B to $95 \%$ B in 20-22 min, and then kept isocratic up to $28 \mathrm{~min}$. Data acquisition and evaluation were performed with the MassLynx V4.1 software (Waters).

The measurement of short-chain organic acids was conducted using a Dionex model ICS 2000 ion chromatograph (IC) equipped with an IonPac AS11-HC analytical column $(4 \times 250 \mathrm{~mm})$ and using $40 \mathrm{mM} \mathrm{KOH}$ as an eluent. All of the experiments were repeated in triplicate and data represented the average of the triplicates.

\subsection{Sample collection, PMA treatment and DNA extraction}

$1 \mathrm{~L}$ effluents of DWDSs, and effluents of DWDSs with CIPCPs were filtered through a $0.2 \mu \mathrm{m}$ polycarbonate filter using a sterile filter funnel and vacuum flask setup, respectively. These were repeated in triplicate, and filters were stored in sterile $2 \mathrm{~mL}$ microfuge tubes before DNA extraction.

Biofilm samples were collected from 3 cast iron coupons in each DWDS. Because the stable corrosion scales have been formed on surface of cast iron coupons, the exterior surfaces of corrosion scales from the DWDSs without and with CIP-CPs were scraped using a sterile metal spatula. Then, the loose solids underneath corrosion scales from the DWDSs without and with CIP-CPs were also collected. The corrosion scales were freeze-dried under vacuum conditions, and then $0.4 \mathrm{~g}$ were weighed and also put into the $2 \mathrm{~mL}$ microfuge tubes before DNA extraction.

Propidium monoazide (PMA) is a dye that penetrates membrane-damaged cells and binds with their DNA [27]. The PMA-bound DNA cannot be amplified in the ensuing PCR. This characteristic is often applied to quantify the DNA of live bacteria and characterize the changes in viable bacterial communities $[28,29]$. In this study, PMA dye (Biotium, Inc., Hayward, CA) was diluted to form a $500 \mu \mathrm{M}$ stock solution. The water and biofilm samples were subjected to PMA treatment by inculbating the polycarbonate membrane filters and $0.4 \mathrm{~g}$ corrosion scales in $40 \mu \mathrm{M}$ PMA solution, respectively. The process of PMA treated samples was in the Supplementary Material (Text S2). After PMA treatment, samples were subjected to DNA extraction with FastDNA SPIN Kit (MP Biomedicals, Solon, OH, USA) following the manufacturer's instructions. DNA quality was checked on an agarose gel, and concentrations were measured with a Nanodrop spectrophotometer (ND-1000,
NanoDrop, USA). All DNA samples were stored at $-80^{\circ} \mathrm{C}$ until further processing.

\subsection{Quantitative PCR}

The quantitative real time polymerase chain reactions (qPCR) of $16 S$ rRNA for total bacteria was performed using the primer pairs $1369 \mathrm{~F}$ and $1492 \mathrm{R}$ with the probe $1389 \mathrm{~F}$ [30]. In addition, the efflux pump which encoding the membrane fusion mexA [31], and the quinolone resistance ( $q n r A, q n r B$ and $q n r S$ ) genes which protect DNA gyrase from the inhibition of quinolones were quantified by qPCR [6]. Primer sequences are presented in Table S2. Standard curves were generated with serial ten-fold dilution $\left(10^{9}\right.$ to $10^{2}$ copies per microliter) of the plasmids. qPCR experiments were carried out with ABI 7300 Fast Real-Time PCR System (Applied Biosystems, Singapore) using premix EX Taq or SYBR premix EX Taq (TaKaRa, Japan) in $20 \mu \mathrm{L}$ reaction volume. The analysis procedures were described in Supplementary Material (Text S3).

\subsection{Sequencing analysis}

To determine the diversity and composition of the bacterial communities, PCR amplications were conducted in triplicate with the 341f (5'-TTACCGCGGCTGCTGGCAC-3') and 806r (5'GGACTACNNGGGTATCTAAT- $3^{\prime}$ ) primer set that amplifies the V3-V4 region of the $16 S$ rRNA gene [32,33]. The PCR process was described in the Supplementary Material (Text S4). The gel electrophoresis of the PCR products, DNA marker and negative controls were shown in Fig. S1. After purification of PCR products and addition of index codes, sequencing libraries were generated. The library was sequenced on an Illumina HiSeq platform and $250 \mathrm{bp}$ paired-end reads were generated at Novogene (Beijing, China).

Paired-end reads from the original DNA fragments are merged by using FLASH (V1.2.7, http://ccb.jhu.edu/software/FLASH/), and the paired-end reads was assigned to each sample according to the unique barcodes. Sequences were analyzed using QIIME (http://qiime.org/index.html) software package (V1.7.0, Quantitative Insights Into Microbial Ecology), and in-house Perl scripts are used to analyze alpha and beta diversity. Then, UPARSE pipeline (V7.0. 1001, http://drive5.com/uprase/) is used to pick operational taxonomic units (OTUs) through making OTU table, and RDP classifier is used to assign taxonomic data to each representative sequence [34]. Sequences were assigned to OTUs at $97 \%$ similarity. OTUs were used to calculate a Bray-Curtis distance matrix, based on which cluster analysis on samples was conducted using $\mathrm{R}$ software (version 3.0.1). CANOCO program (CANOCO 4.5 for windows) is used to run principal component analysis (PCA). Correlations analysis is performed using SPSS (Inc., in Chicago, Illinois) version 19.0 for windows.

\subsection{The SOS/umu bioassay}

The SOS/umu test was carried out according to the method of Oda et al. [35], and the strain S. typhimurium TA1535/pSK1002 was used in this study. The samples pretreatment and SOS/umu test process were described in Supplementary Material (Text S5). The dimethylsulfoxide (DMSO) was used as solvent control, and 4-NQO was used as positive controls. The $\beta$-galactosidase activity (Unit) was calculated as followes:

$\beta$ - galactosidase activity (Unit) $=1000 * \frac{(\text { Abs420 }-1.75 * \text { Abs550) }}{(\mathrm{t} * 0.0667 * \text { Abs595) }}$

where Abs420, Abs550 and Abs595 were the absorbance at $420 \mathrm{~nm}, 550 \mathrm{~nm}$ and $595 \mathrm{~nm}$, and t represents the reaction time (min).

The genotoxicity is assessed by use of the TEQ approach [36,37]. Briefly, the equivalent 4-NQO concentration $\left(\mathrm{TEQ}_{4-\mathrm{NOO}}\right)$ of concen- 
Table 1

The relative amounts of ciprofloxacin chlorination products according to normalized analysis (\%).

\begin{tabular}{lllll}
\hline$m / z$ & $\mathrm{~A}$ & $\mathrm{~B}$ & $\mathrm{C}$ & $\mathrm{D}$ \\
\hline 263 & $0 \pm 0$ & $12.4 \pm 0.95$ & $54.4 \pm 4.53$ & $42.1 \pm 3.65$ \\
288 & $0 \pm 0$ & $1.62 \pm 0.12$ & $1.35 \pm 0.09$ & $0 \pm 0$ \\
297 & $0 \pm 0$ & $2.89 \pm 0.23$ & $4.29 \pm 0.36$ & $1.46 \pm 0.08$ \\
302 & $0 \pm 0$ & $5.17 \pm 0.48$ & $3.61 \pm 0.28$ & $3.38 \pm 0.25$ \\
306 & $0 \pm 0$ & $2.45 \pm 0.22$ & $3.77 \pm 0.26$ & $11.0 \pm 1.03$ \\
332 & $100 \pm 0$ & $0 \pm 0$ & $0 \pm 0$ & $0 \pm 0$ \\
334 & $0 \pm 0$ & $1.24 \pm 0.10$ & $9.64 \pm 0.85$ & $10.7 \pm 0.91$ \\
340 & $0 \pm 0$ & $24.3 \pm 1.83$ & $14.4 \pm 1.02$ & $9.63 \pm 0.86$ \\
350 & $0 \pm 0$ & $32.2 \pm 2.86$ & $7.63 \pm 0.69$ & $0 \pm 0$ \\
366 & $0 \pm 0$ & $8.65 \pm 0.56$ & $0 \pm 0$ & $0 \pm 0$ \\
374 & $0 \pm 0$ & $8.29 \pm 0.47$ & $0 \pm 0$ & $0 \pm 0$ \\
Total & $100 \pm 0$ & $99.2 \pm 0.28$ & $99.1 \pm 0.60$ & $78.3 \pm 0.41$ \\
\hline
\end{tabular}

a Data expressed as average signal intensity of the degradation products normalized to the initial ciprofloxacin signal (\%) and standard deviations of three samples taken during the experiments. A: the raw water with addition of ciprofloxacin (CIP); $\mathrm{B}$ : the raw water with addition of CIP chlorinated for $2 \mathrm{~h}$; C: the raw water with addition of CIP chlorinated for $50 \mathrm{~h}$; D: the effluents of drinking water distribution systems with ciprofloxacin chlorination products (CIP-CPs).

trated waters was calculated based on the dose-response curves for 4-NQO. The equations used are listed below:

$\mathrm{TEQ}_{4-N Q \mathrm{O}}\left(\mu g L^{-1}\right)=$ Slop $_{\text {sample }} /$ Slop $_{4-N Q O}$

\section{Results and discussion}

\subsection{Ciprofloxacin chlorination in plastic bottles}

Ciprofloxicin (CIP) reacted with chlorine quickly, and $1.6 \mathrm{mg} / \mathrm{L}$ $\mathrm{CIP}$ in raw water could be degraded completely after $2 \mathrm{~h}$. However, DOC concentration did not take significant changes after chlorination for $50 \mathrm{~h}(\mathrm{p}>0.05)$ (Fig. S2). CIP in ultrapure water also showed the same tendency. The results verified that chlorination could not induce mineralization of CIP.

Ten intermediate products after CIP reacting with chlorine for different time were identified by UPLC-Q-TOF in Table S3. Due to lack of relevant standards, the relative amounts of different chlorination products were assessed based on their signal intensity relative to the initial CIP signal according to some reports $[4,38]$. After reacting with chlorine for $2 \mathrm{~h}$, the main CIP chlorination products (CIP-CPs) were with molecular ions of $m / z 340,350$, and their relative amounts were $24.3 \%, 32.2 \%$, respectively (Table 1 ). When chlorination continued for $50 \mathrm{~h}$, the relative amounts of products $\mathrm{m} / \mathrm{z} 340$ and 350 decreased to $14.4 \%$ and $7.63 \%$, respectively, and the products $m / z 366,374$ disappeared, while the relative amounts of product $\mathrm{m} / \mathrm{z} 263$ increased from $12.4 \%$ to $54.4 \%$. Therefore, the CIP-CPs went further transformation with continuous chlorination reaction.

A reaction pathway for CIP chlorination was proposed in Scheme 1 according to the results of UPLC-Q-TOF-MS and some other studies $[1,2,39]$. In chlorination process, firstly, reaction between chlorine with piperazine ring of $\operatorname{CIP}(\mathrm{m} / z$ 332) resulted in the formation of $N$-chlorinated derivative (CIP1, $m / z$ 366), which went through rapid imine hydrolysis and loss of $\mathrm{CH}_{2} \mathrm{O}$ to form the desethylene ciprofloxacin (CIP2, $m / z$ 306). This also resulted in opening of the piperazine ring. $N$-Chlorination of CIP2 leaded to produce the derivative with chlorinated ethylenediamine group (CIP 3, m/z 374), which went through hydrolysis and decayed to aniline compound (CIP4, $m / z 263$ ). The direct halogenation of aromatic ring in CIP 4 formed the chlorinated aniline compound (CIP 5, $\mathrm{m} / \mathrm{z}$ 297). Meanwhile, CIP 1 went through direct halogenation, imine hydrolysis and loss of $\mathrm{CH}_{2} \mathrm{O}$ to generate chlorinated desethylene ciprofloxacin (CIP 6, $\mathrm{m} / \mathrm{z} 340$ ). $\mathrm{N}$-Chlorination and hydrolysis of CIP 6 also induced the formation of CIP $5(\mathrm{~m} / \mathrm{z} 297)$. Secondly, oxidation

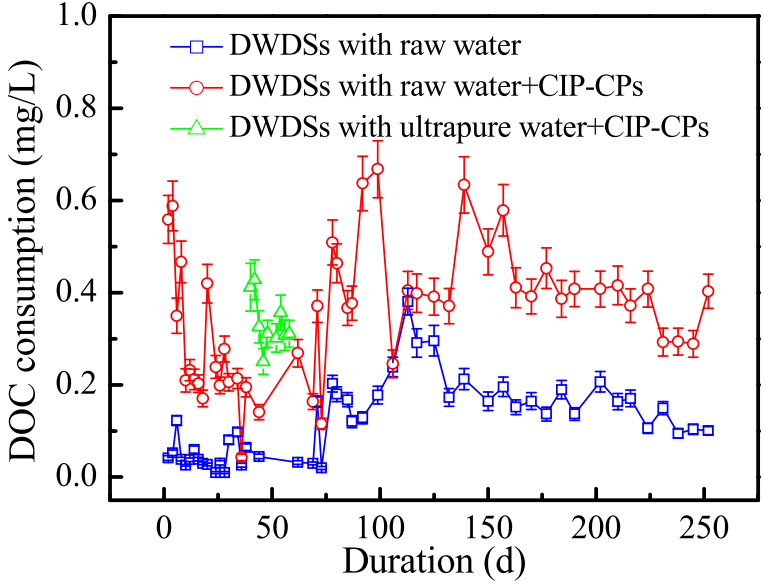

Fig. 1. The DOC consumption in different drinking water distribution systems (DWDSs) with and without ciprofloxacin chlorination products (CIP-CPs). Error bars represent standard deviations of three samples taken during the experiments.

of the piperazine ring in CIP leaded to incorporation of two $\mathrm{O}$ atoms, and then loss of $\mathrm{CO}$ group resulted in opening of piperazine ring (CIP7, $m / z 334$ ). A second loss of a $\mathrm{CO}$ group also leaded to the formation of desethylene ciprofloxacin (CIP2, $m / z$ 306). Oxidation at the aldehyde group of CIP7 generated a carboxylic acid (CIP8, $m / z 350$ ), which also leaded to CIP2 formation after decarboxylation. Loss of the fluorine atom from CIP2 resulted in the formation of defluorinated product (CIP9, $m / z$ 288). Thirdly, oxidation of the quinolone moiety induced defluorination and decarboxylation, leading to the formation of CIP10 ( $\mathrm{m} / \mathrm{z} 302)$.

Both the relative amounts of CIP-CPs and its reaction pathway indicated that the main reaction was the halogenation and oxidation of the piperazine ring, inducing opening of the piperazine ring. And the most relative amount of CIP-CPs was aniline compound (CIP4, $m / z$ 263), in which piperazine ring was completely destroyed after chlorination for $50 \mathrm{~h}$.

\subsection{Biotransformation and biomineralization of CIP-CPs in DWDSs}

Different waters were poured into different drinking water distribution systems (DWDSs) after being chlorinated for $2 \mathrm{~h}$. As shown in Fig. 1, after $48 \mathrm{~h}$ in the DWDSs, the average consumptions of DOC were $0.334,0.353,0.120 \mathrm{mg} / \mathrm{L}$ for ultrapure water with CIP-CPs, raw water with/without CIP-CPs, respectively. DOC removal was different from each other $(p<0.05)$. The results illustrated that $0.233 \mathrm{mg} / \mathrm{L}$ DOC of CIP-CPs in raw water was removed when the water went through the DWDSs, suggesting that the CIPCPs could be mineralized or adsorbed in DWDSs. Many studies have found that the removal of CIP were contributed to the corrosion of zero-valent iron, adsorption and biotransformation [22,40-42]. The tested DWDSs have been used for more than two years, and the stable corrosion scales have been formed on the surface of the iron, therefore, corrosion played little role in the transformation of CIP-CPs in DWDSs. Moreover, the organic matters in the corrosion scales were also extracted and analyzed by UPLC-Q-TOF-MS. The results showed that only the peak intensity of chlorinated desethylene ciprofloxacin (CIP 6, $m / z$ 340) increased after the CIP-CPs went through the DWDSs (Table S4), verifying that this product could be adsorbed onto the corrosion scales.

Furthermore, the intermediates in the effluents of DWDSs were also analyzed. Compared with chlorination alone differently, the derivative with two carboxylic groups (CIP8, $m / z$ 350) and defluorinated product (CIP10, $\mathrm{m} / \mathrm{z} 288$ ) disappeared. Moreover, the relative amounts of aniline compound (CIP4, $m / z$ 263), chlorinated 
<smiles>O=C(O)c1cn(C2CC2)c2cc(N3CCNCC3)c(F)cc2c1=O</smiles>

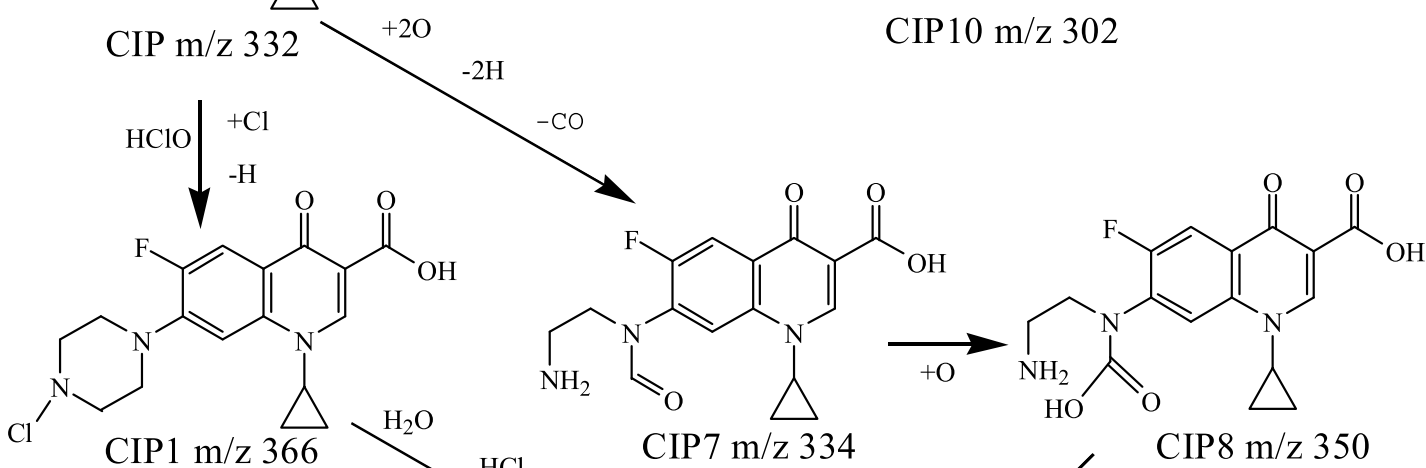<smiles>NCCNc1c(F)c(CCC(O)C(Cl)Cl)c2c(=O)c(C(=O)O)cn(C3CC3)c2c1Cl</smiles>

CIP6 m/z 340<smiles>Nc1c(F)cc2c(=O)c(C(=O)O)cn(C3CC3)c2c1Cl</smiles>

CIP5 m/z 297

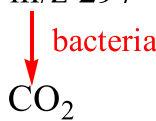

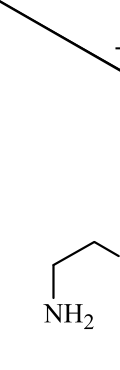

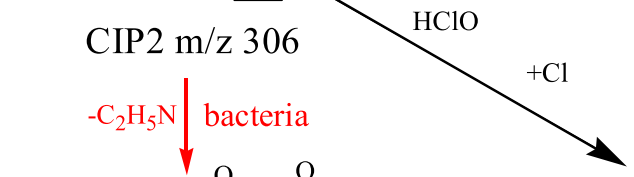

CIP $8 \mathrm{~m} / \mathrm{z} 350$<smiles>Nc1cc2c(cc1F)c(=O)c(C(=O)O)cn2C1CC1</smiles>

CIP3 m/z 374

CIP4 m/z 263<smiles>[R]OC(=O)OCC</smiles>

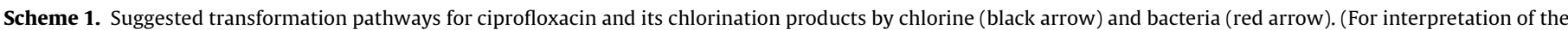
references to colour in this figure legend, the reader is referred to the web version of this article.)

aniline compound (CIP 5, $\mathrm{m} / \mathrm{z}$ 297) and chlorinated desethylene ciprofloxacin (CIP 6, m/z 340) decreased to $42.1 \%, 1.46 \%$ and $9.63 \%$, respectively, while the relative amounts of desethylene ciprofloxacin (CIP 2, $\mathrm{m} / \mathrm{z}$ 306) increased to $11.0 \%$ (Table 1 ). The above results indicated that the decrease/disappearance of some CIP-CPs came from the biotransformation and biomineralization in DWDSs.

$7.63 \%$ of the derivative with two carboxylic groups (CIP8, $\mathrm{m} / \mathrm{z}$ 350 ) went through decarboxylation at the piperazinyl substituent to form desethylene ciprofloxacin (CIP 2, $\mathrm{m} / \mathrm{z} 306$ ), and then loss of $\mathrm{C}_{2} \mathrm{H}_{5} \mathrm{~N}$ group from CIP2 resulted in the formation of aniline compound (CIP4, $\mathrm{m} / \mathrm{z}$ 263) (Scheme 1 ). The compounds $\mathrm{m} / \mathrm{z} 306$ and 263 were also the biotransformation products in most studies $[22,23,43]$. Moreover, one study had indicated that the [4-C] of quinolone ring (Scheme 1 ) was easily mineralized by the microbe to form $\mathrm{CO}_{2}$ [43]. Therefore, $12.3 \%$ of the aniline compound (CIP4, $m / z$ 263), 7.60\% of chlorinated aniline compound (CIP 5, $m / z 297$ ) and $1.35 \%$ of defluorinated product (CIP10, $\mathrm{m} / z$ 288) may be biomineralized in DWDSs (Scheme 1). Although $\mathrm{CO}_{2}$ concentration was not analyzed in this study, the average concentration of oxalic acid was found to increase from $30 \mu \mathrm{g} / \mathrm{L}$ to $53 \mu \mathrm{g} / \mathrm{L}$ in the effluents of DWDSs obviously ( $p<0.01$ ) (Fig. S3). The result indicated that some CIP-CPs may go through biotranformation to form oxalic acid, and then it was bio-mineralized in DWDSs. Moreover, the total relative amounts also decreased about $21 \%$, which was consistent with the removal of about $0.2 \mathrm{mg} / \mathrm{L}$ DOC of CIP-CPs in DWDSs.

During the transformation process of CIP-CPs in DWDSs, all the compounds which went through biotransformation and biomineralization did not have the piperazine ring. However, the relative amounts of CIP10 which had the intact piperazine ring did not take great changes (Table 1). Therefore, the destruction of the piperazine ring of CIP induced by chlorination alone resulted in the 


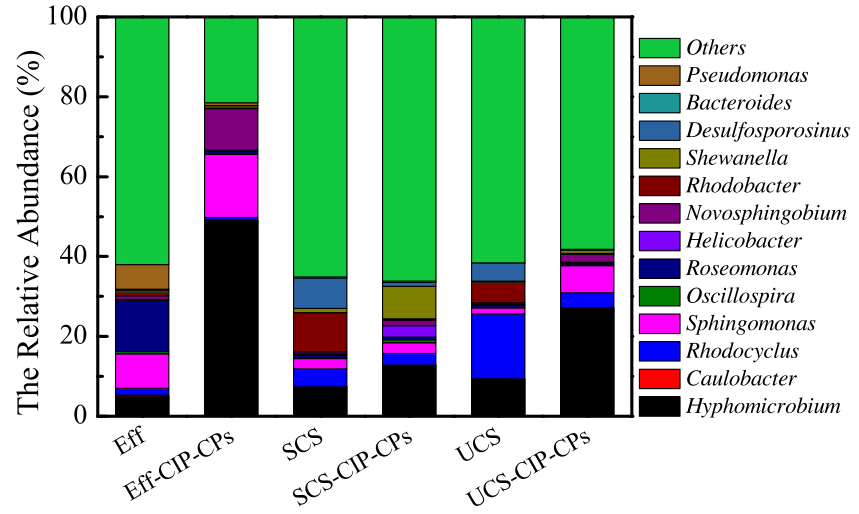

Fig. 2. Relative abundance of bacterial genera in different samples, Eff = effluents of the drinking water distribution systems (DWDSs) without ciprofloxacin chlorination products (CIP-CPs); Eff-CIP-CPs = effluents of DWDSs with CIP-CPs; SCS, UCS = the biofilm samples on surface and underneath of corrosion scales in DWDSs without CIP-CPs; SCS-CIP-CPs, UCS-CIP-CPs = the biofilm samples on surface and underneath of corrosion scales in DWDSs with CIP-CPs. The bacterial genera, relative abundance of which was lower than $1 \%$ in all samples, were classified into others.

biotransformation and biomineralization of the CIP-CPs in DWDSs. The chlorine and bacteria played a synergistic effect on the transformation of CIP-CPs in DWDSs.

\subsection{Interaction of CIP-CPs and bacteria in DWDSs}

The water and biofilm samples were collected when the biotransformation of CIP-CPs reached a relative stable stage after 250 days (Fig. S4). All the samples were subjected to PMA treatment $[28,29]$ and the live bacterial communities were analyzed. From all the samples, 228308 valid sequences and 4950 OTUs at $97 \%$ similarity level were obtained (Table S5). The lower Chao 1 and Shannon indices of the samples from DWDSs with CIP-CPs indicated the less bacterial diversity and richness in this type of DWDSs.

At phylum level, Proteobacteria predominated in bacterial communities of all samples (Fig. S5). However, at class level, Alphaproteobacteria, Betaproteobacteria and Gammaproteobacteria in the effluents and biofilms exhibited different distribution between two DWDSs with/without CIP-CPs (Fig. S6). Moreover, the dominant bacteria were compared at the genus level for different samples (Fig. 2). In the effluents of DWDSs without CIP-CPs, the main bacterial genera were Roseomonas, Sphingomonas, Pseudomonas and Hyphomicrobium, and their relative abundance were $12.8 \%, 8.62 \%, 6.18 \%$ and $4.89 \%$, respectively. However, in the effluents of DWDSs with CIP-CPs, Roseomonas and Pseudomonas greatly decreased, and the main bacterial genera became Hyphomicrobium (48.9\%), Sphingomonas (15.8\%) and Novosphingobium (10.4\%). In the biofilms in DWDSs without CIP-CPs, both of surface and underneath of corrosion scales had similar bacterial community composition, and Desulfosporosinus, Hyphomicrobium, Rhodobacter and Rhodocyclus predominated in the bacterial communities. However, in DWDSs with CIP-CPs, Desulfosporosinus, Rhodobacter and Rhodocyclus decreased obviously, and Hyphomicrobium (12.7\%), Shewanella $(8.07 \%)$ and Helicobacter $(2.91 \%)$ became the main bacterial genera in biofilms on surface of corrosion scales, meanwhile, Hyphomicrobium (26.9\%), Sphingomonas (6.83\%) and Novosphingobium $(1.99 \%)$ were the main bacteria genera in biofilms underneath of corrosion scales. Furthermore, the relative abundance of most bacteria at species level was lower than $1 \%$ (Table S6). Comparing with the DWDSs without CIP-CPs, the relative abundance of Alcaligenes decreased from $6.13 \%$ to $0.66 \%$ in the effluents of DWDSs with CIP-CPs, and the relative abundance of Meridiei and Mexicanus also decreased obviously in biofilms. However, Infantis and Moorei increased to $0.25 \%$ and $0.33 \%$ in biofilms on surface of corrosion

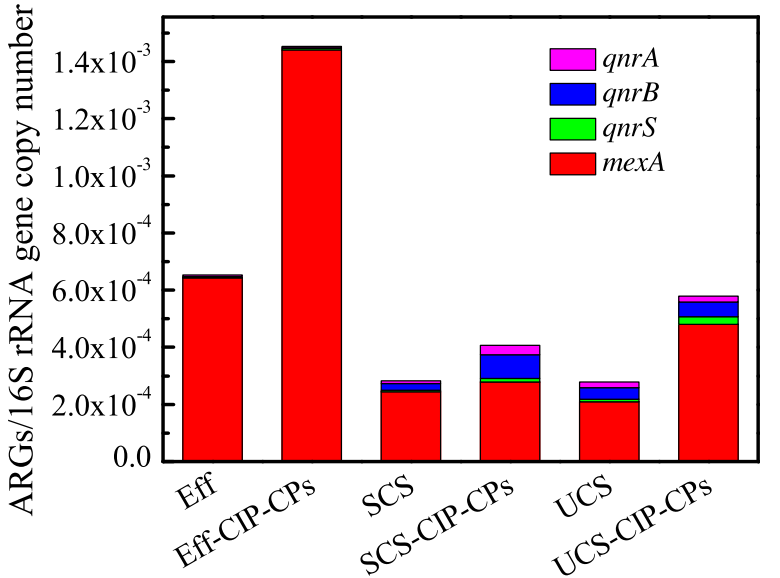

Fig. 3. Ralative abundance of antibiotic resistance genes (ARGs) presented as gene copy number per $16 \mathrm{~S}$ rRNA in effluents and biofilms.

scales in DWDSs with CIP-CPs, respectively. Gnavus increased to $0.13 \%$ in biofilms underneath of corrosion scales. Therefore, CIP-CPs changed the bacterial communities in the effluents and biofilms of DWDSs.

Correspondingly, the gene copy number of $16 S$ rRNA decreased in DWDSs with CIP-CPs (Fig. S7), which was due to the decrease of some bacteria. The product CIP10 with intact piperazine ring and aromatic ring took little change in DWDSs, and it may have great effect on the inactivation of these bacteria. Moreover, the quinolone moiety of CIP did not take great changes during chlorination process, and the CIP-CPs still had antibacterial activity [22]. Therefore, the bacterial community composition could be changed by the antimicrobial selective pressure of CIP-CPs in DWDSs. The results also induced the enrichment of the bacterial genera Helicobacter, Hyphomicrobium, Novosphingobium, Shewanella and Sphingomonas which could grow by using the CIP-CPs in DWDSs, resulting in the biotransformation and biomineralization of some CIP-CPs.

Furthermore, the antibiotic resistance genes (ARGs) including effluents pump gene mexA and quinolone rsistance genes (qnr) were analyzed by qPCR (Fig. S7). The main ARGs in effluents and biofilms was mexA, the gene copy number was about $10^{2}$ gene copies/mL water and $10^{4}$ gene copies/g corrosion scales, respectively. Moreover, the gene copy number of qnr was about $10^{3}$ gene copies/g corrosion scales in biofilms. Comparing with DWDSs without CIP-CPs, the relative abundance of mexA and qnrS gene copy number, which was as the percentage of $16 S$ rRNA gene copy number, increased 1 -fold in the effluents and biofilms underneath of corrosion scales in DWDSs with CIP-CPs, meanwhile, the relative abundance of $q n r A$ and $q n r B$ gene copy number increased 3-fold in biofilms on surface of corrosion scales in DWDSs with CIP-CPs (Fig. 3). The results paralleled to the increase of the bacterial genera Helicobacter, Hyphomicrobium, Novosphingobium, Shewanella and Sphingomonas in DWDSs with ICP-CPs, indicating that the ARGs possibly existed the advantage in these bacterial genera, leading to different distribution of bacterial community in DWDSs with/without CIP-CPs.

Principal component analysis (PCA) and correlation analysis of the relative abundance of bacterial genera and the relative abundance of ARGs mexA, qnrA, qnrB and qnrS were processed (Table S7 and Fig. S8). Obviously, Desulfosporosinus, Pseudomonas, Rhodobacter, Rhodocyclus and Roseomonas did not correlate with all the ARGs, which was consistent with their inactivation in DWDSs. It has been verified that CIP can interact with DNA gyrase and topoisomerase, blocking DNA replication to cause cell death [44]. The results suggested that these bacteria without ARGs were inactivated by the CIP-CPs in DWDSs. 


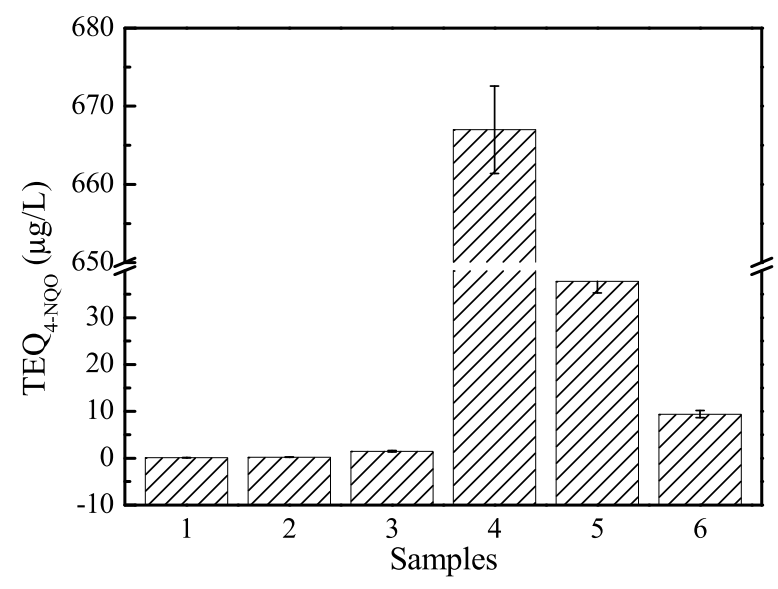

Fig. 4. The $\mathrm{TEQ}_{4-\mathrm{NQO}}$ values of different water samples. $1=$ raw water; 2 =raw water chlorinated for $50 \mathrm{~h} ; 3=$ effluents of the drinking water distribution systems (DWDSs) without ciprofloxacin chlorination products (CIP-CPs); $4=$ raw water with addition of ciprofloxacin (CIP); 5 = raw water with addition of CIP chlorinated for $50 \mathrm{~h} ; 6=$ effluents of DWDSs with CIP-CPs. Error bars represent standard deviations of three samples taken during the experiments.

In contrast, mexA and qnrS positively correlated with Hyphomicrobium, Sphingomonas and Novosphingobium ( $\mathrm{p}<0.05$ ), while qnrA and $q n r B$ positively correlated with Shewanella and Helicobacter $(\mathrm{p}<0.05)$, which also indicated that the changes of the ARGs paralleled to bacterial genera in DWDSs. The efflux pump gene mexA was the most ARG in waters, correspondingly, Hyphomicrobium, Novosphingobium and Sphingomonas were the dominated bacterial genera in effluents, suggesting that the important mechanism of these bacterial genera resistance to CIP-CPs in waters was efflux pump. This was consistent with some reports, which found the bacteria could increase their resistance to CIP by the activity of efflux pumps [5,31]. Some other studies had also indicated that plasmidmediated resistance genes $q n r A, q n r B$ and $q n r S$ could produce proteins that can bind to DNA gyrase, protecting it from the action of quinolones such as CIP, and efflux pumps acted to lower the intracellular quniolone concentrations $[31,45]$. Therefore, the bacterial genera Hyphomicrobium, Sphingomonas, Novosphingobium, Shewanella and Helicobacter in biofilms had antibiotic resistance to CIP-CPs due to ARGs mexA and qnr.

\subsection{Environmental relevance}

The genotoxicity caused by the addition of CIP was very high, but its $\mathrm{TEQ}_{4-\mathrm{NOO}}$ decreased from $667 \mu \mathrm{g} / \mathrm{L}$ to $37.7 \mu \mathrm{g} / \mathrm{L}$ after chlorination for $50 \mathrm{~h}$ (Fig. 4). The result indicated that the destruction of piperazine ring in chlorination alone process reduced the genotoxicity obviously $(p<0.05)$. Moreover, chlorination induced destruction of piperazine ring of CIP, causing the decrease of the antibacterial activity. The CIP-CPs resulted in the enrichment of some bacterial genera with ARGs, and these bacteria induced the biotransformation and biomineralization of some CIP-CPs without piperazine ring. Therefore, the synergistic effects of chlorine and bacteria in DWDSs on the transformation of CIP-CPs made TEQ 4 -NQO in effluents of DWDSs decreased to $9.41 \mu \mathrm{g} / \mathrm{L}$ (Fig. 4), which was at the same order of magnitude to that in effluents of DWDSs without CIP-CPs. However, the antibiotic bacteria also drove ARGs mexA, $q n r A, q n r B$ and $q n r S$ promotion. The enrichment and spread of bacteria with ARGs in DWDSs is a growing threat to human health. To reduce the potential risk, the chemical treatment may be superior to the biotransformation for the elimination of antibiotics.

\section{Conclusions}

The results verified that CIP was not mineralized during chlorination process, but its piperazine ring was destroyed. Some CIP-CPs without piperazine ring went further biotranformation and biomineralization in DWDSs. By the bacterial role, the derivative with two carboxylic groups went through decarboxylation to form desethylene ciprofloxacin, and then loss of $\mathrm{C}_{2} \mathrm{H}_{5} \mathrm{~N}$ group generated aniline compound. Furthermore, the aniline compound, chlorinated aniline compound and defluorinated product were bio-mineralized. Therefore, the chlorine initiated the subsequent biotransformation of CIP-CPs, and chlorine and bacteria played a synergistic effect on the transformation of CIP-CPs in DWDSs. This induced the obvious decrease of the genotoxicity in the effluents of DWDSs. Moreover, CIP-CPs also induced the enrichment of the bacterial genera Helicobacter, Hyphomicrobium, Novosphingobium, Shewanella and Sphingomonas in DWDSs. These bacterial genera were contributed to the biotransformation and biomineralization of CIP-CPs. However, the relative abundance of mexA and qnrS gene copy number increased 1 -fold in the effluents and the relative abundance of qnrA and qnrB gene copy number increased 3-fold in biofilms on surface of corrosion scales in DWDSs with CIP-CPs. It verified that the increase of antibiotic resistance genes (ARGs) came from the growth of those bacterial genera by PCA and correlation analysis. These findings indicated that biotransformation of antibiotics might increase the risk of ARGs in DWDSs.

\section{Acknowledgments}

This work was funded by the National Natural Science Foundation of China (No. 51290281), the project of Chinese Academy of Sciences (QYZDY-SSW-DQC004) and the Federal Department of Chinese Water Control and Treatment (Nos. 2017ZX07108, 2017ZX07501002).

\section{Appendix A. Supplementary data}

Supplementary data associated with this article can be found, in the online version, at http://dx.doi.org/10.1016/j.jhazmat.2017.06. 033.

\section{References}

[1] M.C. Dodd, A.D. Shah, U.V. Gunten, C.H. Huang, Interactions of fluoroquinolone antibacterial agents with aqueous chlorine: reaction kinetics, mechanisms, and transformation pathways, Environ. Sci. Technol. 39 (2005) 7065-7076.

[2] Y.F. Ji, C. Ferronato, A. Salvador, X. Yang, J.M. Chovelon, Degradation of ciprofloxacin and sulfamethoxazole by ferrous-activated persulfate: implications for remediation of groundwater contaminated by antibiotics, Sci. Total Environ. 472 (2014) 800-808

[3] A.C. Johnson, V. Keller, E. Dumont, J.P. Sumpter, Assessing the concentrations and risks of toxicity from the antibiotics ciprofloxacin sulfamethoxazole, trimethoprim and erythromycin in European rivers, Sci. Total Environ. 511 (2015) 747-755.

[4] C. Liu, V. Nanaboina, G.V. Korshin, W.J. Jiang, Spectroscopic study of degradation products of ciprofloxacin, norfloxacin and lomefloxacin formed in ozonated wastewater, Water Res. 46 (2012) 5235-5246.

[5] S.Y. Jia, P. Shi, Q. Hu, B. Li, T. Zhang, X.X. Zhang, Bacterial community shift drives antibiotic resistance promotion during drinking water chlorination, Environ. Sci. Technol. 49 (2015) 12271-12279.

[6] C. Rutgersson, J. Fick, N. Marathe, E. Kristiansson, A. Janzon, M. Angelin, A. Johansson, Y. Shouhce, C.F. Flach, D.G.J. Larsson, Fluoroquinolones and qnr genes in sediment water, soil, and human fecal flora in an environment polluted by manufacturing discharges, Environ. Sci. Technol. 48 (2014) 7825-7832

[7] K.P. Weber, M.R. Mitzel, R.M. Slawson, R.L. Legge, Effect of ciprofloxacin on microbiological development in wetland mesocosms, Water Res. 45 (2011) 3185-3196.

[8] A.J. Watkinson, E.J. Murby, D.W. Kolpin, S.D. Costanzo, The occurrence of antibiotics in an urban watershed: from wastewater to drinking water, Sci. Total. Environ. 407 (2009) 2711-2723. 
[9] Z. Ye, H.S. Weinberg, Macrolide quinolone, and tetracycline antibiotics in chlorinated drinking water using liquid chromatography electrospray tandem mass spectrometry, Anal. Chem. 79 (2007) 1135-1144.

[10] H. Wang, N. Wang, B. Wang, Q. Zhao, H. Fang, C. Fu, C. Tang, F. Jiang, Y. Zhou, Y. Chen, Q. Jiang, Antibiotics in drinking water in Shanghai and their contribution to antibiotic exposure of school children, Environ. Sci. Technol. 50 (2016) 2692-2699.

[11] S. Li, X. Zhang, Y. Huang, Zeolitic imidazolate framework-8 derived nanoporous carbon as an effective and recyclable adsorbent for removal of ciprofloxacin antibiotics from water, J. Hazard. Mater. 321 (2017) 711-719.

[12] J.Q. Xiong, M.B. Kurade, J.R. Kim, H.S. Roh, B.H. Jeon, Ciprofloxacin toxicity and its co-metabolic removal by a freshwater microalga Chlamydomonas xexicana, J. Hazard. Mater. 323 (2017) 212-219.

[13] A. Novo, S. Andre, P. Viana, O.C. Nunes, C.M. Manaia, Antibiotic resistance, antimicrobial residues and bacterial community composition in urban wastewater, Water Res. 47 (2013) 1875-1887.

[14] A.L. Cordova-Kreylos, K.M. Scow, Effects of ciprofloxacin on salt marsh sediment microbial communites, ISME J. 1 (2007) 585-595.

[15] Z.H. Diao, X.R. Xu, D. Jiang, G. Li, J.J. Liu, L.J. Kong, L.Z. Zuo, Enhanced catalytic degradation of ciprofloxacin with $\mathrm{FeS}_{2} / \mathrm{SiO}_{2}$ microspheres as heterogeneous Fenton catalyst: kinetics, reaction pathways and mechanism, J. Hazard. Mater. 327 (2017) 108-115.

[16] H.S. Ou, J.S. Ye, S. Ma, C.H. Wei, N.Y. Gao, J.Z. He, Degradation of ciprofloxacin by $\mathrm{UV}$ and $\mathrm{UV} / \mathrm{H}_{2} \mathrm{O}_{2}$ via multiple-wavelength ultraviolet light-emitting diodes: effectiveness, intermediates and antibacterial activity, Chem. Eng. J. 289 (2016) 391-401.

[17] E.D. Bel, J. Dewulf, B.D. Witte, H.V. Langenhove, C. Janssen, Influence of pH on the sonolysis of ciprofloxacin: biodegradability, ecotoxicity and antibiotic activity of its degradation products, Chemosphere 77 (2009) 291-295.

[18] C.K. Gomez-Smith, T.M. LaPara, R.M. Hozalski, Sulfate reducing bacteria and mycobacteria dominate the biofilm communities in a chloraminated drinking water distribution system, Environ. Sci. Technol. 49 (2015) 8432-8440.

[19] B. Li, T. Zhang, pH significantly affects removal of trace antibiotics in chlorination of municipal wastewater, Water Res. 46 (2012) 3703-3713.

[20] M. Mahdi-Ahmed, S. Chiron, Ciprofloxacin oxidation by UV-C activated peroxymonosulfate in wastewater, J. Hazard. Mater. 265 (2014) 41-46.

[21] C. Girardi, J. Greve, M. Lamshoft, I. Fetzer, A. Miltner, A. Schaffer, M. Kastner, Biodegradation of ciprofloxacin in water and soil and its effects on the microbial communities, J. Hazard. Mater. 198 (2011) 22-30.

[22] A. Prieto, M. Moder, R. Rodil, L. Adrian, E. Marco-Urrea, Degradation of the antibiotics norfloxacin and ciprofloxacin by a white-rot fungus and identification of degradation products, Bioresour. Technol. 102 (2011) 10987-10995.

[23] Q. Zeng, S.H. Zhang, J. Liao, D.Y. Miao, X.Y. Wang, P. Yang, L.J. Yun, A.L. Liu, W.Q. Lu, Evaluation of genotoxic effects caused by extracts of chlorinated drinking water using a combination of three different bioassays, J. Hazard. Mater. 296 (2015) 23-29.

[24] E.P.A. of China, Analysis Method for Water and Waste Water, 4th edition Press of Chinese Environmental Science, Beijing, 2002.

[25] H. Wang, S. Masters, M.A. Edwards, J.O. Falkinham III, A. Pruden, Effect of disinfectant, water age, and pipe materials on bacterial and eukaryotic community structure in drinking water biofilm, Environ. Sci. Technol. 48 (2014) 1426-1435

[26] H. Liu, K.D. Schonberger, C.Y. Peng, J.F. Ferquson, E. Desormeaux, P. Meyerhofer, H. Luckenbach, G.V. Korshin, Effects of blending of desalinated and conventionally treated surface water on iron corrosion and its release from corroding surfaces and pre-existing scales, Water Res. 47 (2013) 3817-3826.

[27] S.H. Zhang, C.S. Ye, H.R. Lin, L. Lv, X. Yu, UV disinfection induces a vbnc state in Escherichia coli and pseudomonas aeruginosa, Environ. Sci. Technol. 49 (2015) $1721-1728$.
[28] E.T. Gensberger, M. Polt, M. Konrad-Koszler, P. Kinner, A. Sessitsch, T. Kostic Evaluation of quantitative PCR combined with PMA treatment for molecular assessment of microbial water quality, Water Res. 67 (2014) 367-376.

[29] T.H. Chiao, T.M. Clancy, A. Pinto, C.W. Xi, L. Raskin, Differential resistance of drinking water bacterial populations to monochloramine disinfection, Environ. Sci. Technol. 48 (2014) 4038-4047.

[30] P. Gao, C. Gu, X. Wei, X. Li, H. Chen, H. Jia, Z. Liu, G. Xue, C. Ma, The role of zero valent iron on the fate of tetracycline resistance genes and class 1 integrons during thermophilic anaerobic co-digestion of waste sludge and kitchen waste, Water Res. 111 (2017) 92-99.

[31] M. Tandukar, S. Oh, U. Tezel, K.T. Konstantinidis, S.G. Pavlostathis, Long-term exposure to benzalkonium chloride disinfectants results in change of microbial community structure and increased antimicrobial resistance, Environ. Sci. Technol. 47 (2013) 9730-9738.

[32] A.K. Bartram, M.D.J. Lynch, J.C. Stearns, G. Moreno-Hagelsieb, J.D. Neufeld, Generation of multimillion-sequence 16S rRNA gene libraries from complex microbialcommunities by assembling paired-end Illumina reads, Appl. Environ. Microbiol. 77 (2011) 3846-3852.

[33] J.A. Peiffer, A. Spor, O. Koren, Z. Jin, S.G. Tringe, J.F. Dangl, E.S. Buckler, R.E. Ley, Diversity and heritability of the maize rhizosphere microbiome under field conditions, Proc. Natl. Acad. Sci. U. S. A. 110 (2013) 6548-6553.

[34] Q. Wang, G.M. Garrity, J.M. Tiedje, J.R. Cole, Naïve Bayesian classifier for rapid assignment of rRNA sequences into the new bacterial taxonomy, Appl. Environ. Microbiol. 73 (2007) 5261-5267.

[35] Y. Oda, K. Funasaka, M. Kitano, A. Nakama, T. Yoshikura, Use of a high-throughput umu-microplate test system for rapid detection of genotoxicity produced by mutagenic carcinogens and airborne particulate matter, Environ. Mol. Mutagen. 43 (2004) 10-19.

[36] Y. Yan, W.W. Jiang, N. Li, M. Ma, D.H. Wang, Z.J. Wang, K.F. Rao, Assessing of genotoxicity of 16 centralized source-waters in China by means of the SOS/umu assay and the micronucleus test: initial identification of the potential genotoxicants by use of a GC/MS method and the QSAR Toolbox 3.0, Mutat. Res. 763 (2014) 36-43.

[37] Y. Chang, Y. Bai, Q. Ji, Y. Huo, H. Liu, J.C. Crittenden, J. Qu, Combined genotoxicity of chlorinated products from tyrosine and benzophenone-4, J. Hazard. Mater. 322 (2017) 387-393.

[38] M. Cvancarova, M. Moeder, A. Filipova, T. Reemtsma, T. Cajthaml, Biotransformation of the antibiotic agent flumequine by ligninolytic fungi and residual antibacterial activity of the transformation mixtures, Environ. Sci. Technol. 47 (2013) 14128-14136.

[39] B. Dewitte, J. Dewulf, K. Demeestere, P.D. Wispelaere, H.V. Langenhove, Ozonation of ciprofloxacin in water: HRMS identification of reaction products and pathways, Environ. Sci. Technol. 42 (2008) 4889-4895.

[40] D. Wunder, V.A. Bosscher, R.C. Cok, R.M. Hozalski, Sorption of antibiotics to biofilm, Water Res. 45 (2011) 2270-2280.

[41] J.A.D.L. Perini, B.F. Silva, R.F.P. Nogueira, Zero-valent iron mediated degradation of ciprofloxacin-assessment of adsorption, operational parameters and degradation products, Chemosphere 174 (2014) 345-352.

[42] X.Y. Gu, Y.Y. Tan, F. Tong, C. Gu, Surface complexation modeling of coadsorption of antibiotic ciprofloxacin and $\mathrm{Cu}(\mathrm{II})$ and onto goethite surfaces, Chem. Eng. J. 269 (2015) 113-120.

[43] H.G. Wetzstein, M. Stadler, H.V. Tichy, A. Dalhoff, W. Karl, Degradation of ciprofloxacin by basidiomycetes and identification of metabolites generated by the brown rot fungus Gloeophyllum striatum, Appl. Environ. Microbiol. 65 (1999) 1556-1563.

[44] E. Marti, B. Huerta, S.R. Mozaz, D. Barcelo, J. Jofre, J.L. Balcazar, Characterization of ciprofloxacin-resistant isolates from a wastewate treatment plant and its receiving river, Water Res. 61 (2014) 67-76.

[45] M. Broszat, H. Nacke, R. Blasi, C. Siebe, J. Huebner, R. Daniel, E. Grohmann, Wastewater irrigation increases the abundance of protentially harmful gammaproteobacteria in soils in Mezquital Valley Mexico, Appl. Environ. Microbiol. 80 (2014) 5282-5291. 